\title{
Low SAR, Simple Printed Compact Multiband Antenna for Mobile and Wireless Communication Applications
}

\author{
K. S. Sultan, H. H. Abdullah, and E. A. Abdallah \\ Microstrip and Microwave Engineering Departments, Electronics Research Institute, 33 El Bohouth St., Dokki, Giza 12622, Egypt \\ Correspondence should be addressed to H. H. Abdullah; haythm_eri@yahoo.com
}

Received 2 May 2014; Revised 30 June 2014; Accepted 13 July 2014; Published 27 August 2014

Academic Editor: Wenhua Yu

Copyright (C) 2014 K. S. Sultan et al. This is an open access article distributed under the Creative Commons Attribution License, which permits unrestricted use, distribution, and reproduction in any medium, provided the original work is properly cited.

\begin{abstract}
Simple multiband planar antenna for wireless communication applications is presented. The proposed antenna performs four resonant modes covering multibands of wireless standards, including LTE 700, GSM, DCS, PCS, UMTS, and LTE 2300/2500. Furthermore, it covers the ISM, WiMAX, and the WLAN bands. The geometry of the proposed antenna consists of a single FR4 substrate where an open cavity fed by a coplanar U-shaped monopole is etched on one side and a short-circuited meander line in the opposite side. The cavity by its nature supports a wide range of higher frequencies, while its boundary that consists of a thin monopole resonates at $900 \mathrm{MHz}$. The meander line in the opposite side supports the LTE 700 band. The operating bands ranges are $(680-748 \mathrm{MHz}),(870-960 \mathrm{MHZ}),(1.36-1.59 \mathrm{GHz})$, and $(1.71-2.56 \mathrm{GHz})$. The antenna size is $30 \times 18 \times 0.8 \mathrm{~mm}^{3}$. The antenna not only has a compact size but also supports a low SAR radiation at all the operating frequencies. The proposed antenna is tested using the four recommended test positions of the CTIA association where the proposed antenna reveals good performance in all test cases in the presence of handset (keypad, battery, speaker camera, RF circuit, and LCD) in talking position, and in standby position.
\end{abstract}

\section{Introduction}

With the vast increase of mobile services and with the introduction of compact electronics, there is a great demand for developing new low specific absorption rate (SAR) antenna with compact size that is compatible with the compact electronic components sizes. Also, the future development of the personal communication devices will aim to provide image, voice, and data communication at any time. This indicates that mobile devices are required to support different technologies and operate in different frequency bands. So, the LTE (long term evolution) is a new high-performance air interface standard for cellular mobile communication systems. It is the 4 th generation $(4 \mathrm{G})$ of radio technologies to increase the capacity and speed of mobile telephone networks $[1,2]$.

Several studies have been performed to produce an antenna structure able to satisfy the demands of low SAR compact multiband antenna for use in hand-held devices [2-7]. Miniaturisation techniques with control circuits were introduced [3-6]; however, they had problems such as low antenna efficiency because of insertion loss in lumped elements, as well as an increased cost. Multilayer has been used for the multiband antenna method; however, they have certain disadvantages that cause high loss as well as high cost.

In order to include LTE bands, Guo et al. [5] introduced a new compact multiband antenna to cover GSM 900, DCS 1800, PCS 1900, UMTS 2100, and some LTE bands (FDD-LTE bands 1-6 and 8-10 and TDD-LTE bands 19, 20, and 33-37) with dimensions of $50 \times 15 \times 4 \mathrm{~mm}^{3}$. Also, Chen and Jhang [6] introduced a compact multiband antenna that consists of a direct-fed monopole with a chip inductor, a grounded strip, and a coupled-fed monopole with a distributed inductor and dimensions of $75 \times 10 \times 0.8 \mathrm{~mm}^{3}$. Recently, Elsheakh and Abdallah [8] introduced a new compact multiband printed inverted-F antenna (IFAs) with dimensions $35 \times 45 \mathrm{~mm}^{2}$ which covers GSM, LTE, UMTS, Bluetooth, and WLAN (at $-6 \mathrm{~dB})$.

In this paper, a new compact size, single layer planar antenna, is proposed. The new antenna has dimensions of 


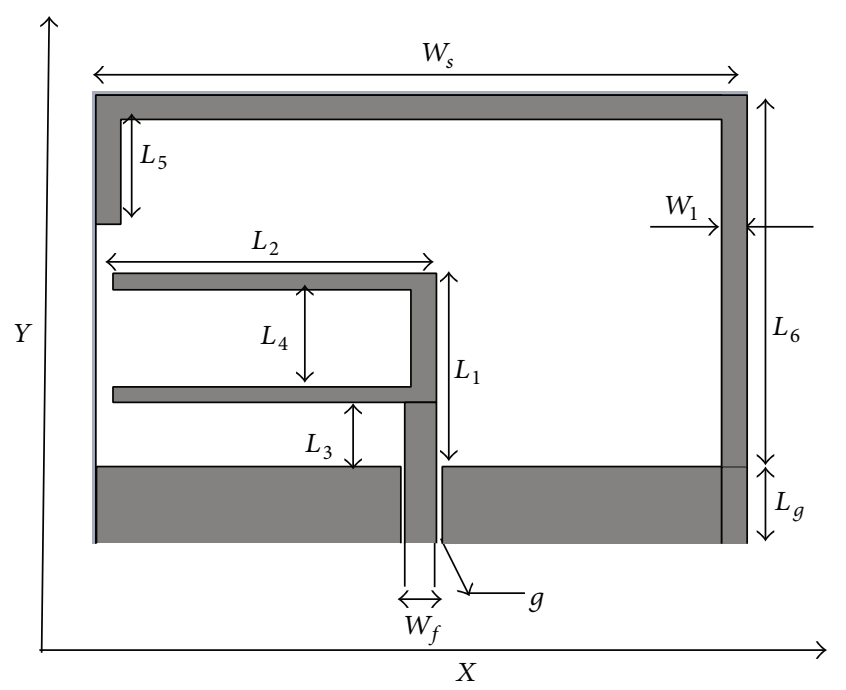

(a) Front view

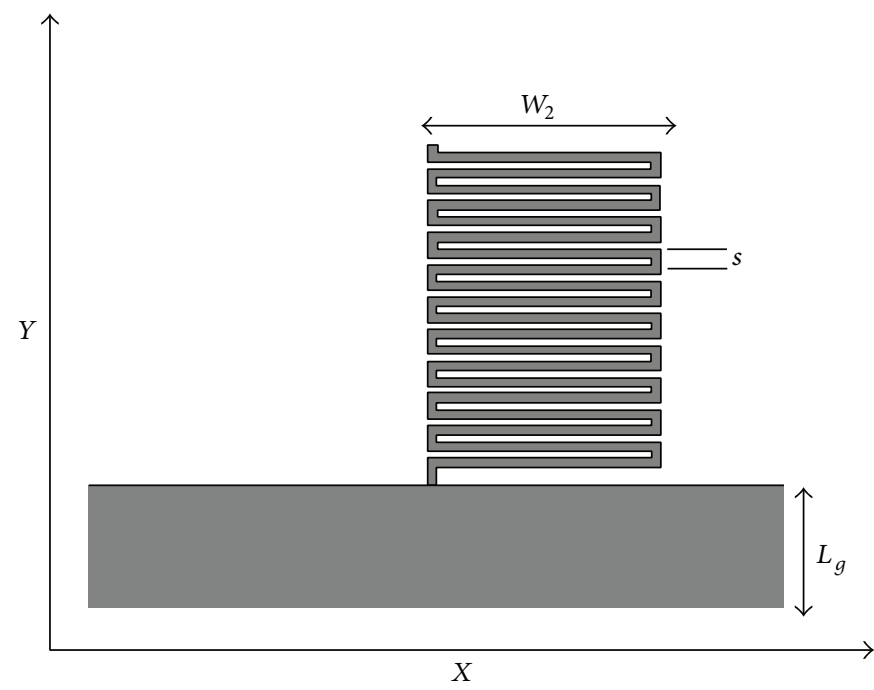

(b) Back view

FIGURE 1: Geometry of the proposed antenna: (a) front view and (b) back view.

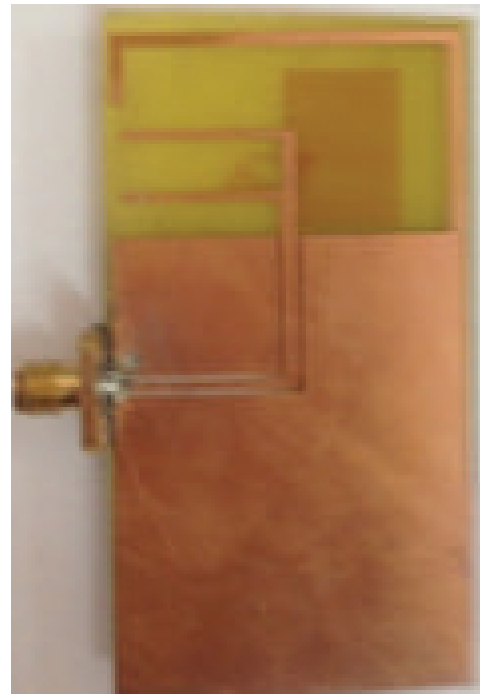

(a) Front view

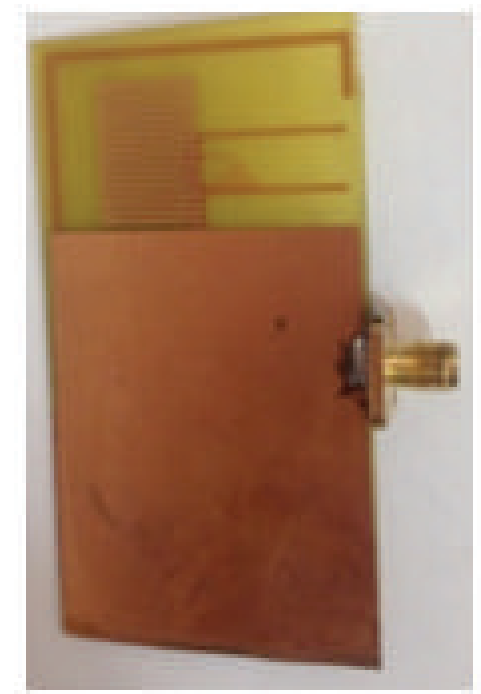

(b) Back view

FIGURE 2: Prototype of the proposed antenna: (a) front view and (b) back view.

$30 \times 18 \times 0.8 \mathrm{~mm}^{3}$. It covers the following operating bands; GSM 900, DCS 1800, PCS 1900, UMTS 2100, ISM 2450, almost LTE bands (FDD-LTE bands 1-4, 7-12, 15-17, and 2325 and TDD-LTE bands 33-38), WiMAX (2.3-2.4 GHz, 2.5$2.56 \mathrm{GHz})$, and WLAN $(2.4-2.5 \mathrm{GHz})$.

\section{Antenna Design}

The proposed antenna is a planar microstrip antenna with compact dimensions of $(30 \times 18 \times 0.8) \mathrm{mm}^{3}$. So, the antenna can be easily integrated in small and sleek mobile device. Figure 1 shows the geometry of the proposed antenna. All the labeled dimensions are tabulated in Table 1. The proposed antenna is designed over FR4 substrate $\left(\varepsilon_{r}=4.5\right)$ with $0.8 \mathrm{~mm}$ thickness and loss tangent of 0.025 .

The antenna is composed of an open cavity excited by a U-shaped monopole fed in a coplanar way. The electrical length of the monopole is a quarter-wavelength at $2.1 \mathrm{GHz}$. The cavity radiates in the range from $1.71 \mathrm{GHz}$ to $2.5 \mathrm{GHz}$. In order to support the GSM 900 application, the arm length of the cavity is designed to resonate at $900 \mathrm{MHz}$. The most challenging resonance is the LTE 700 which necessitates a long branch that consumes more area of the antenna. In order to overcome this problem a meander line is etched on the opposite side of the antenna where it is fed by aperture coupling. The meander line has the advantage of having long length in a very small area but at the expense 
TABLE 1: Geometrical parameters of the proposed antenna.

\begin{tabular}{lccccc}
\hline Parameter & $\begin{array}{c}\text { Value } \\
(\mathrm{mm})\end{array}$ & Parameter & $\begin{array}{c}\text { Value } \\
(\mathrm{mm})\end{array}$ & Parameter & $\begin{array}{c}\text { Value } \\
(\mathrm{mm})\end{array}$ \\
\hline$L_{1}$ & 10 & $L_{5}$ & 6 & $W_{f}$ & 1.5 \\
$L_{2}$ & 17 & $L_{6}$ & 18 & $W_{s}$ & 30 \\
$L_{3}$ & 3 & $W_{1}$ & 1.5 & $g$ & 0.25 \\
$L_{4}$ & 5 & $W_{2}$ & 9 & $s$ & 0.9 \\
$L_{g}$ & 5 & & & & \\
\hline
\end{tabular}

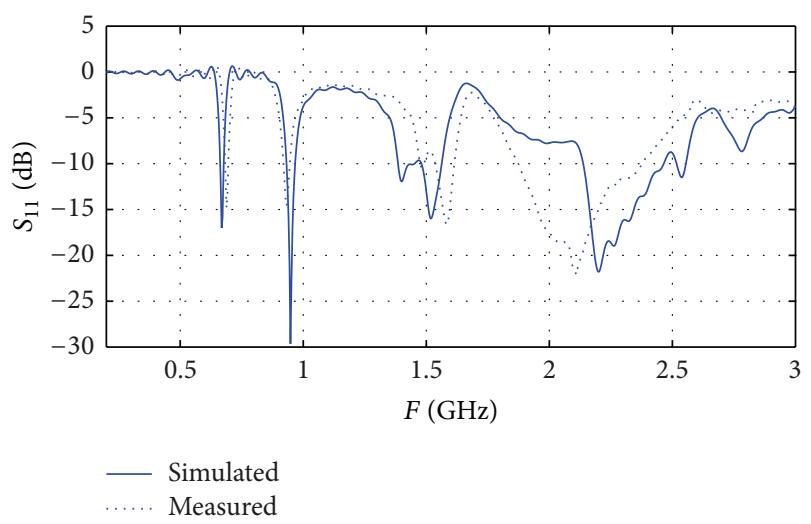

FIGURE 3: Measured and simulated reflection coefficient of the proposed antenna.

of its high impedance which complicates the matching. This problem is solved by ending the meander line by a rectangular conducting slab connected to the ground.

Compared to the 3D structure of the PIFA antennas, the proposed antenna is via free antenna and has a simple structure that effectively reduces the manufacturing costs and complexity. A prototype of the antenna is fabricated as shown in Figure 2.

The proposed antenna was simulated using the CST Microwave Studio 2012. Figure 3 shows a comparison between the simulated and measured results of the reflection coefficient. The simulated and the experimental results ensure that the antenna covers all the aforementioned mobile and wireless applications bands. Taking the $6 \mathrm{~dB}$ return loss as a reference, the antenna operates in the four bands (680-748 MHz), (870-960 MHZ), (1.36-1.59 GHz), and $(1.71-2.56 \mathrm{GHz})$ to cover GSM 900, DCS 1800, PCS 1900, UMTS 2100, ISM 2450, most LTE bands, WLAN, Bluetooth, and Wi-Fi. The ground plane on the lower part of PCB has an area of $30 \times 50 \mathrm{~mm}^{2}$, representing a typical system board of mobile terminals. The ground plane below the radiator is removed for coupling between the radiator and the meander line. The effect of ground plane is taken into consideration as shown in Figure 4. It is noticed that the length of ground plane affects the matching slightly. Figure 5 shows the measured and simulated radiation patterns at frequencies $0.9,1.8$, and $2.1 \mathrm{GHz}$ in free space. Radiation pattern measurements were carried out using SATIMO Anechoic antenna chamber where the available frequency range starts from $0.8 \mathrm{GHz}$.

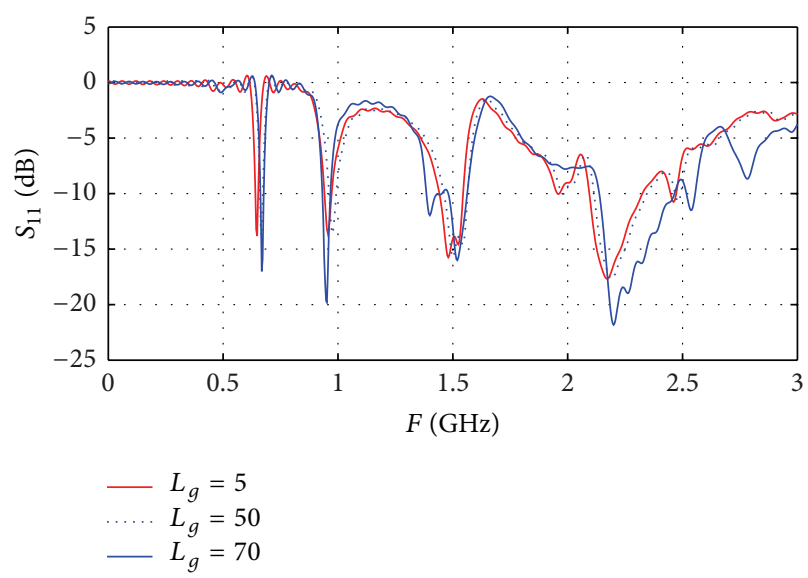

FIGURE 4: The effect of ground plane length against frequency.

TABLE 2: Gain and the radiation efficiency of the proposed antenna.

\begin{tabular}{|c|c|c|c|c|c|}
\hline \multicolumn{2}{|l|}{$F(\mathrm{GHz})$} & 0.7 & 0.9 & 1.8 & 2.1 \\
\hline \multirow{2}{*}{ Gain dBi } & Simulated & 2.1 & 1.8 & 2.3 & 2.7 \\
\hline & Measured & - & 1.55 & 1.8 & 2.5 \\
\hline \multirow{2}{*}{ Radiation efficiency \% } & Simulated & 69 & 74 & 78.2 & 79.6 \\
\hline & Measured & - & 69 & 72.5 & 77.4 \\
\hline
\end{tabular}

TABLE 3: Characteristics of the mobile parts.

\begin{tabular}{lcc}
\hline Mobile parts & Material type & $\varepsilon_{r}$ \\
\hline LCD & LCD film & 4.78 \\
Battery & PEC & - \\
Rf circuit & PEC & - \\
Side key, function keys & Rubber & 3.5 \\
Camera & PEC & - \\
Speaker & PEC & - \\
Casing (housing) & PVC & 2.8 \\
PCB & FR4 & 4.5 \\
\hline
\end{tabular}

Table 2 shows the values of gain and radiation efficiency of the proposed antenna.

It is worth illustrating the degradation of the radiation pattern in presence of the human body model. As shown in Figure 6, the simulated radiation in the presence of the human body is directed away from the human body due to the high reflection of the head materials. Thus, the nature of the human body itself contributes to lowering the SAR within the human body.

\section{Handset Modeling}

The smart phone has a number of components besides the system circuit board and the antenna. Figure 7 shows mobile Samsung Galaxy SIII with standard dimensions (136.6 $\times$ $\left.70.6 \times 8.6 \mathrm{~mm}^{3}\right)$. The antenna is assembled with battery, camera, speaker, RF circuit, and touch screen LCD. The 
$F(\mathrm{GHz})$

0.9

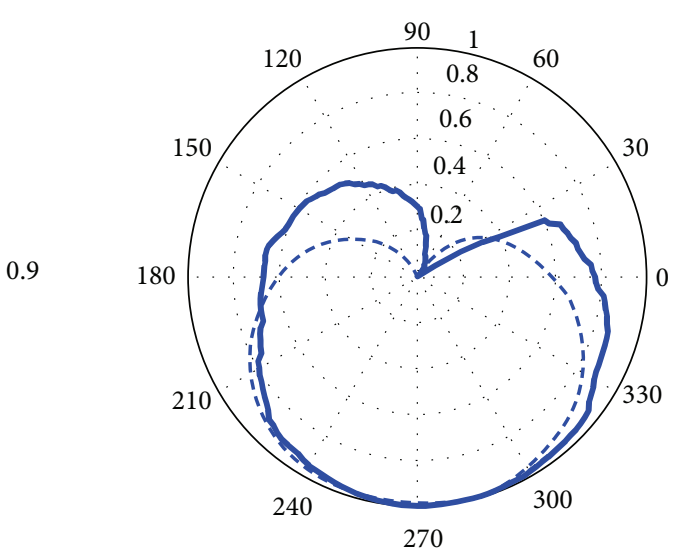

1.8

2.1
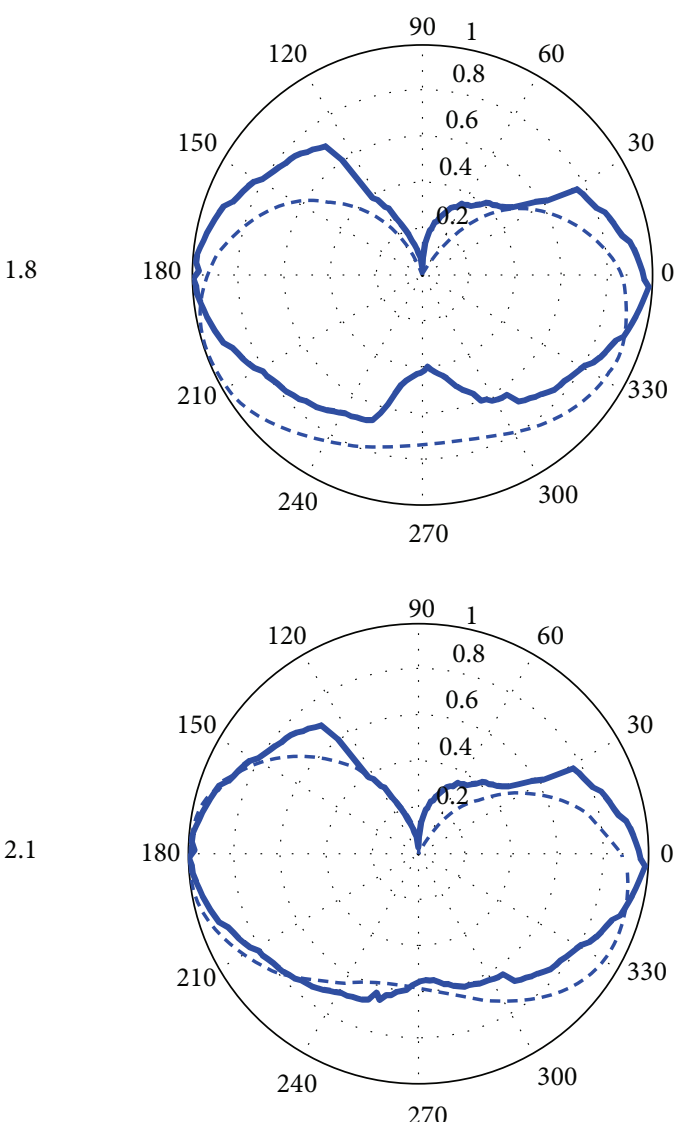
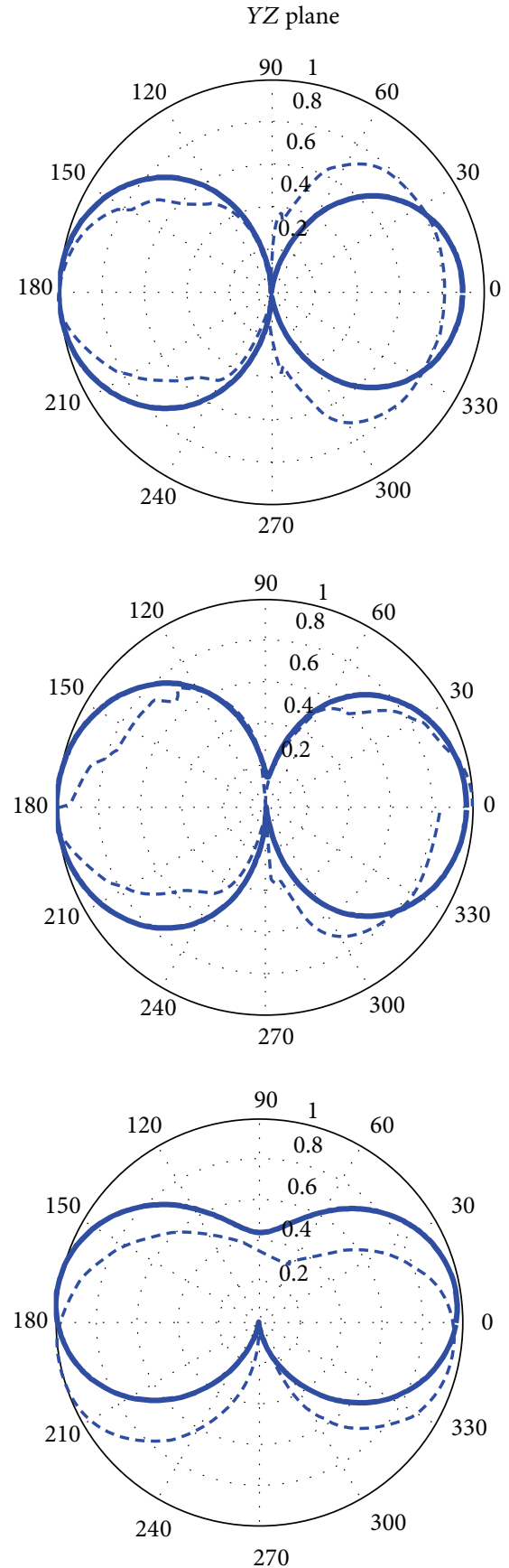

FIgURE 5: The radiation pattern in the $X Z$ and $Y Z$ planes. The antenna is in the $X Y$ plane: simulated (solid line); measured (dash line).

housing of the mobile is a polyvinyl chloride material (PVC) with permittivity of 2.8 and loss tangent of 0.019 where the total dimensions of the mobile are $136.6 \times 70.6 \times 8.6 \mathrm{~mm}^{3}$ and its wall thickness is $1 \mathrm{~mm}$. The camera has a diameter of $5 \mathrm{~mm}$, and $4 \mathrm{~mm}$ thickness. Opposite to the camera is a speaker with the dimensions of $15 \mathrm{~mm}$ length and $6 \mathrm{~mm}$ width; a battery with volume $70 \times 50 \times 3 \mathrm{~mm}^{3}$ and a large touch LCD with size $110 \times 60 \times 2 \mathrm{~mm}^{3}$ are connected to the main circuit board via connectors. Table 3 shows the characteristics of the mobile parts.

CTIA has proposed several body test cases for a mobile phone as shown in Figure 8, namely, mobile handset in free space, browsing mode, talking position, and talking position with hand [9]. Figure 9 shows the return loss of the antenna in the 4 different cases. The primary effect of the hand and head has little shift and degradation in the impedance matching. 
$F(\mathrm{GHz})$
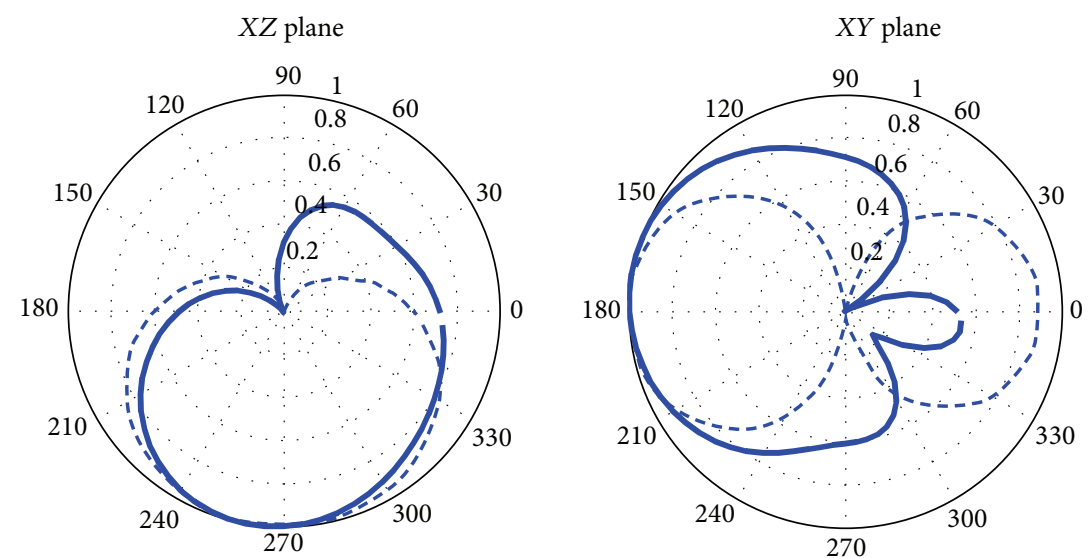

0.9
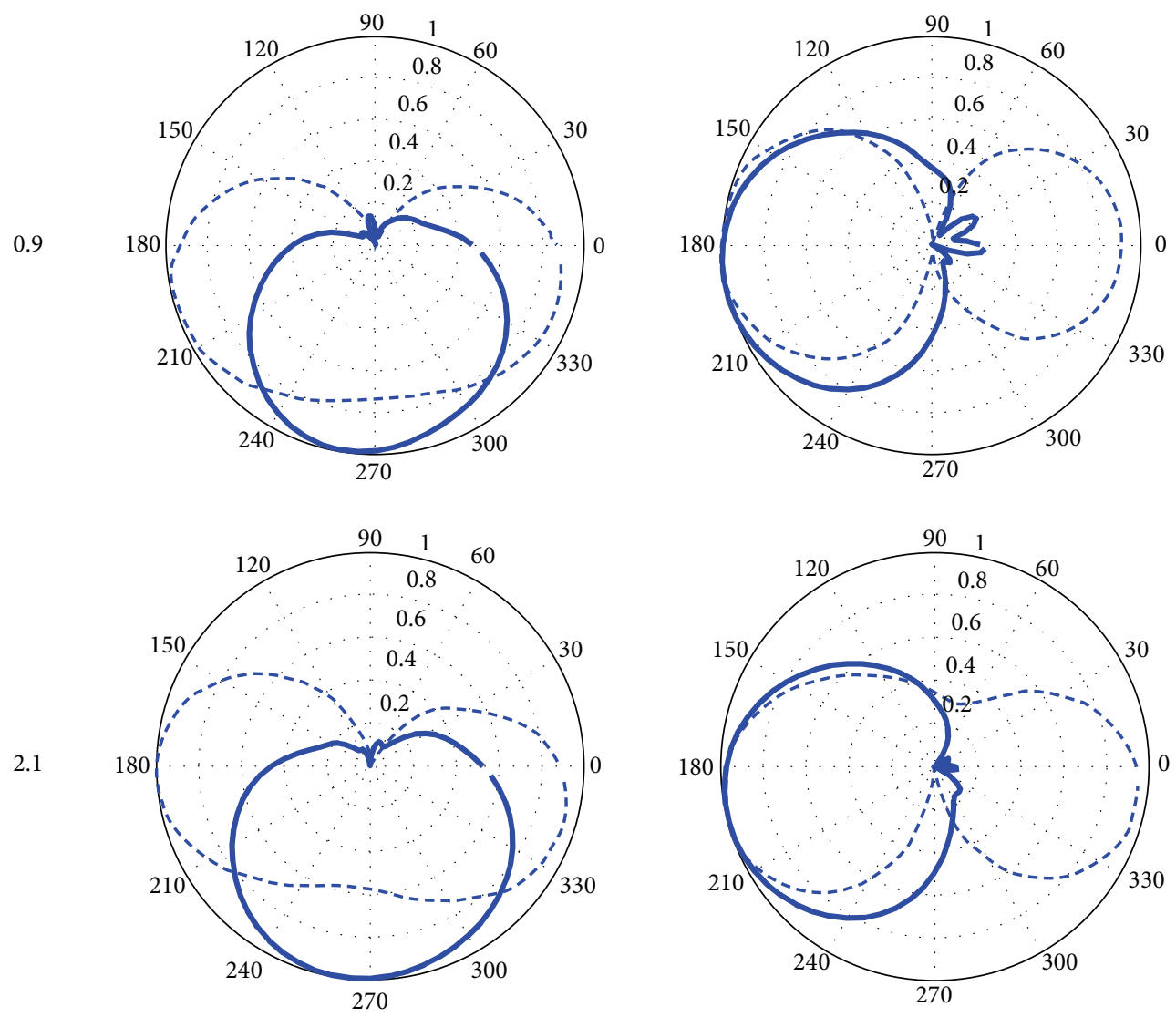

Figure 6: The simulated radiation pattern in the $X Z$ and $X Z$ planes. The antenna is in the $Y Z$ plane: without human body (Dash line); with human body (Solid line).

However, the impedance matching over the operating bands is still acceptable for practical applications of the mobile phone.

\section{SAR Calculation}

As the use of the mobile phone is increased, the research on the health risk due to the electromagnetic (EM) fields generated from wireless terminals is widely in progress. Many factors may affect the EM interaction while using cellular handset in close proximity to head and hand. One of the most widely used parameters for the evaluation of exposure is SAR, specific absorption rate. Therefore, some regulations and standards have been issued to limit the radiation exposure from the mobile handsets not only to decrease the SAR but also to increase the antenna systems efficiency. The SAR limit specified in IEEE C95.1-2005 has been updated to $2 \mathrm{~W} / \mathrm{kg}$ over any $10 \mathrm{~g}$ of tissue [10], which is comparable to the limit specified in the International Commission on Non-Ionizing Radiation Protection (ICNIRP) guidelines [11]. 


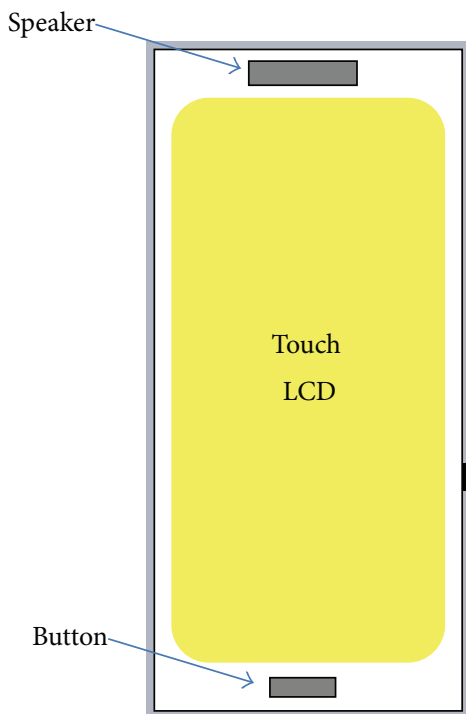

(a) Front view

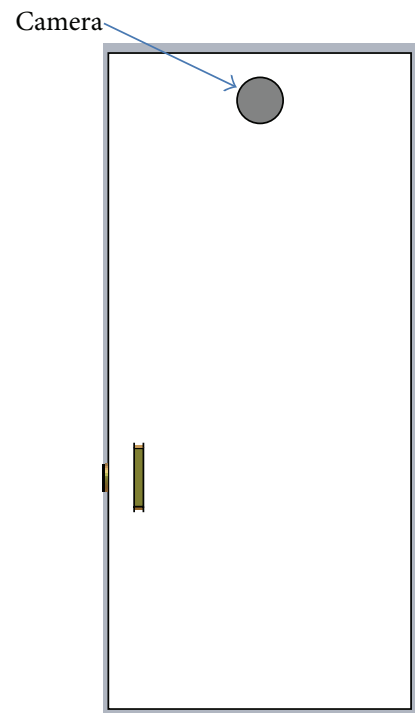

(b) Back view

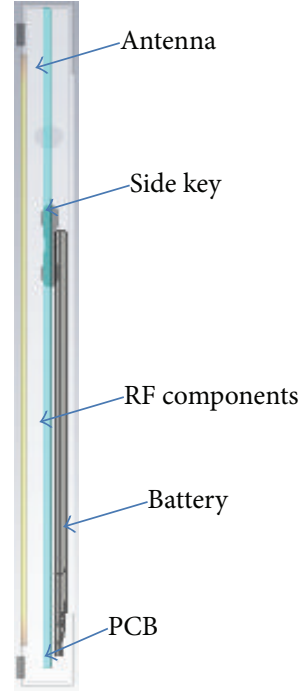

(c) Side view

FIGURE 7: Structure of mobile handset: (a) front, (b) back, and (c) side view.

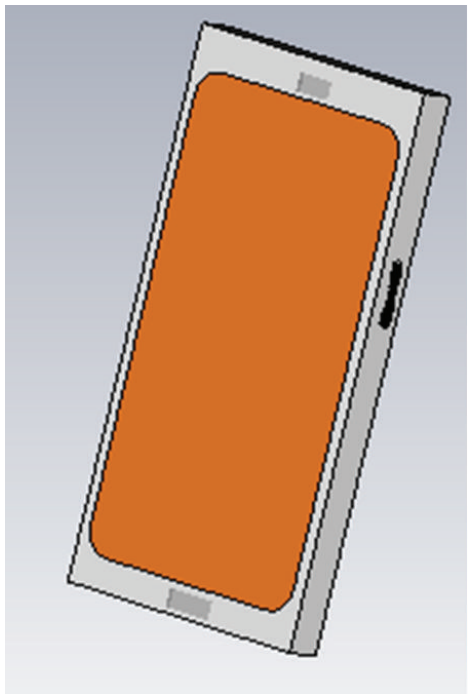

(a)

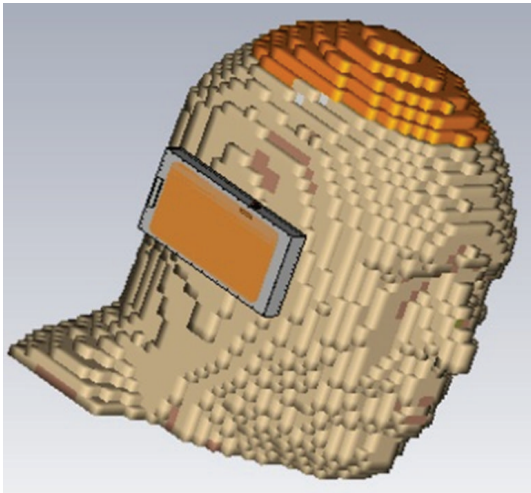

(c)

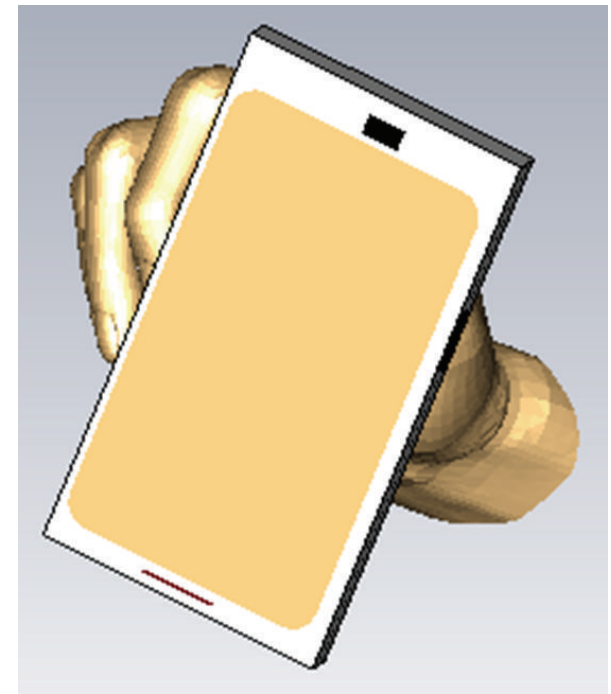

(b)

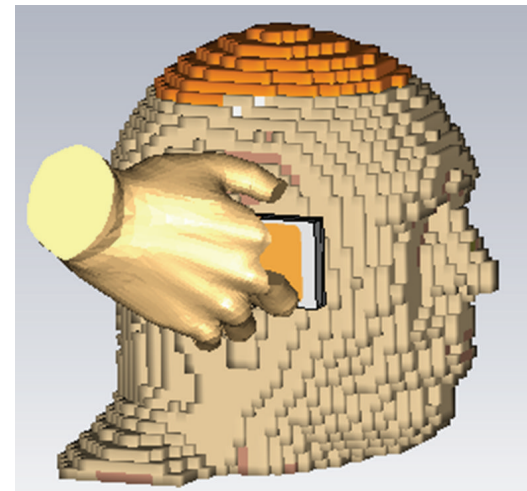

(d)

FIGURE 8: CTIA-defined four different test positions: (a) free space, (b) browsing mode, (c) talking position, and (d) talking position with hand. 
TABLE 4: SAR values and the effects of human model on antenna properties.

\begin{tabular}{lccccc}
\hline$F(\mathrm{GHz})$ & \multirow{2}{*}{ SAR $(\mathrm{W} / \mathrm{kg})(10 \mathrm{~g})$} & $S_{11} \mid(\mathrm{dB})$ & $\begin{array}{c}\text { In free space } \\
\text { Radiation efficiency }(\%)\end{array}$ & $\left|S_{11}\right|(\mathrm{dB})$ & $\begin{array}{c}\text { With human model } \\
\text { Radiation efficiency }(\%)\end{array}$ \\
\hline 0.7 & 0.98 & -17 & 69 & -15.5 & 66.5 \\
0.9 & 0.93 & -29.5 & 74 & -29 & 70.6 \\
1.8 & 0.80 & -8 & 78.2 & -7.2 & 72.8 \\
2.1 & 1.2 & -10 & 79.6 & -9.4 & 73.3 \\
\hline
\end{tabular}

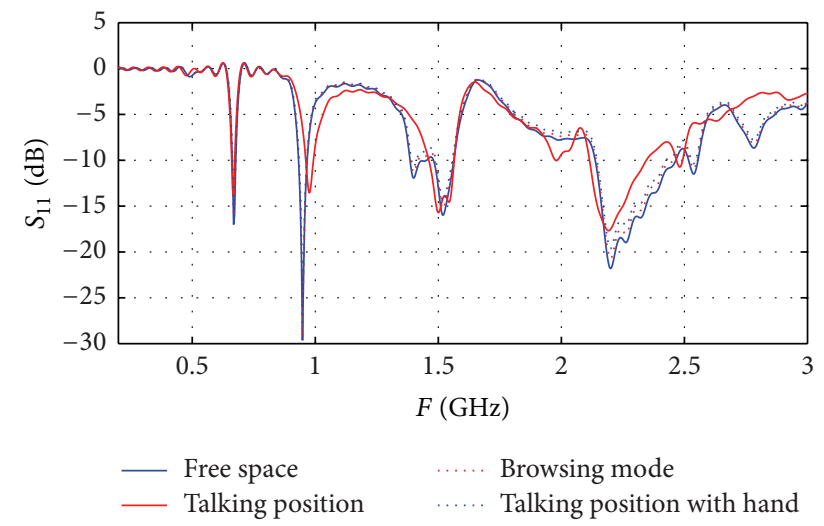

FIgURE 9: The simulated return loss of antenna in mobile handset in four different test positions.

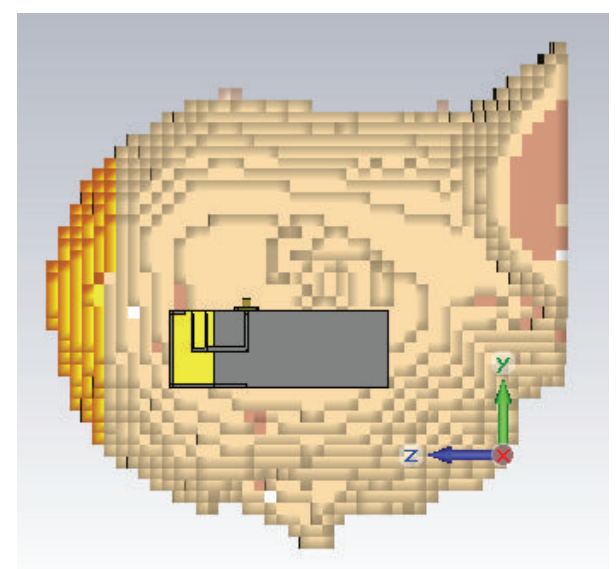

FIGURE 10: Antenna structure with the human head model (Hugo voxel model).

In this paper, The SAR calculations on human head model are done in the presence of the antenna in the $Z Y$ plane as shown in Figure 10. The SAR is tested at 0.7, 0.9, 1.8, and $2.1 \mathrm{GHz}$ when the antenna is close to the human head and the output power of the cellular phone is set to $500 \mathrm{~mW}$. The SAR calculations are done using the CST 2012 commercial package with Hugo model CST Microwave Studio [12]; the tissues that are contained have relative permittivities and conductivities, according to [13]. The tissues frequency dispersive properties are taken into consideration.

Table 4 shows the maximum SAR at the aforementioned operating frequencies when the antenna is close to the body; the radiation efficiency and $S_{11}$ are also shown in Table 3 in free space and with human model.

\section{Conclusion}

A new compact planar antenna design that supports all of the operating mobile services, ISM applications, and wireless communication services is introduced. The SAR values of the antenna satisfy the standard safety guidelines. The antenna has more compact size when compared to other published antennas. The antenna was simulated using the CST simulator and fabricated using the photolithographic technique. Very good agreement is obtained between the simulated and the experimental results.

\section{Conflict of Interests}

The authors declare that there is no conflict of interests regarding the publication of this paper.

\section{Acknowledgment}

This work is funded by the National Telecom Regulatory Authority (NTRA), Ministry of Communications and Information Technology (MCIT), Egypt.

\section{References}

[1] S. Sesia, I. Toufik, and M. Baker, LTE-The UMTS Long Term Evolution: From Theory to Practice, Wiley, Chichester, UK, 2009.

[2] R. A. Bhatti, S. Yi, and S. Park, "Compact antenna array with port decoupling for LTE-standardized mobile phones," IEEE Antennas and Wireless Propagation Letters, vol. 8, pp. 1430-1433, 2009.

[3] K.-L. Wong, Y. C. Lin, and B. Chen, "Internal patch antenna with a thin air-layer substrate for GSM/DCS operation in a PDA phone," IEEE Transactions on Antennas and Propagation, vol. 55, no. 4, pp. 1165-1172, 2007.

[4] M. Martínez-Vázquez, O. Litschke, M. Geissler, D. Heberling, A. M. Martínez-González, and D. Sánchez-Hernández, "Integrated planar multiband antennas for personal communication handsets," IEEE Transactions on Antennas and Propagation, vol. 54 , no. 2, pp. 384-391, 2006.

[5] Q. Guo, R. Mittra, F. Lei, Z. Li, J. Ju, and J. Byun, "Interaction between internal antenna and external antenna of mobile phone and hand effect," IEEE Transactions on Antennas and Propagation, vol. 61, no. 2, pp. 862-870, 2013. 
[6] W. S. Chen and W. C. Jhang, "A planar WWAN/LTE antenna for portable devices," IEEE Antennas and Wireless Propagation Letters, vol. 12, pp. 19-22, 2013.

[7] K. S. Sultan, H. H. Abdullah, E. A. Abdallah, and E. A. Hashish, "Low SAR, miniaturized printed antenna for mobile, ISM, and WLAN service," Antennas and Wireless Propagation Letters, vol. 12, pp. 1106-1109, 2013.

[8] D. Elsheakh and E. Abdallah, "Compact multiband printed IFA on electromagnetic band-gap structures ground plane for wireless applications," International Journal of Microwave Science and Technology, vol. 2013, Article ID 248501, 9 pages, 2013.

[9] CTIA Certification Department Program, Test Plan for Mobile Station over the Air Performance Method of Measurement for Radiated RF Power and Receiver Performance, http://www.ctia.org/.

[10] IEEE C95.1-2005, IEEE Standards for Safety Levels with Respect to Human Exposure to Radio Frequency Electromagnetic Fields, $3 \mathrm{kHz}$ to $300 \mathrm{GHz}$, Institute of Electrical and Electronics Engineers, New York, NY, USA, 2005.

[11] International Non-Ionizing Radiation Committee of the International Radiation Protection Association, "Guidelines on limits on exposure to radio frequency electromagnetic fields in the frequency range from $100 \mathrm{kHz}$ to $300 \mathrm{GHz}$," Health Physics, vol. 54, no. 1, pp. 115-123, 1988.

[12] “CST Microwave Studio Suite 2011 User's Manual," http:// www.cst.com.

[13] S. Gabriel, R. W. Lau, and C. Gabriel, “The dielectric properties of biological tissues: II. Measurements in the frequency range $10 \mathrm{~Hz}$ to $20 \mathrm{GHz}$," Physics in Medicine and Biology, vol. 41, no. 11, pp. 2251-2269, 1996. 

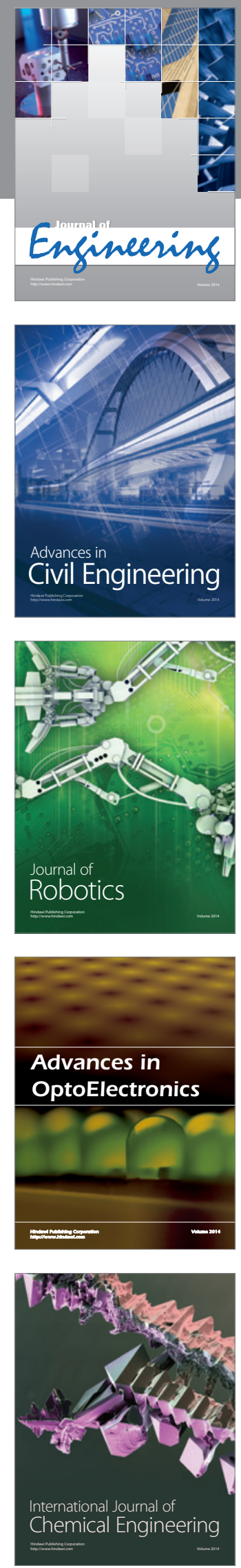

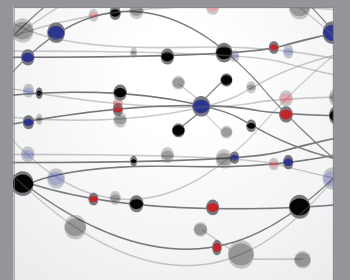

The Scientific World Journal
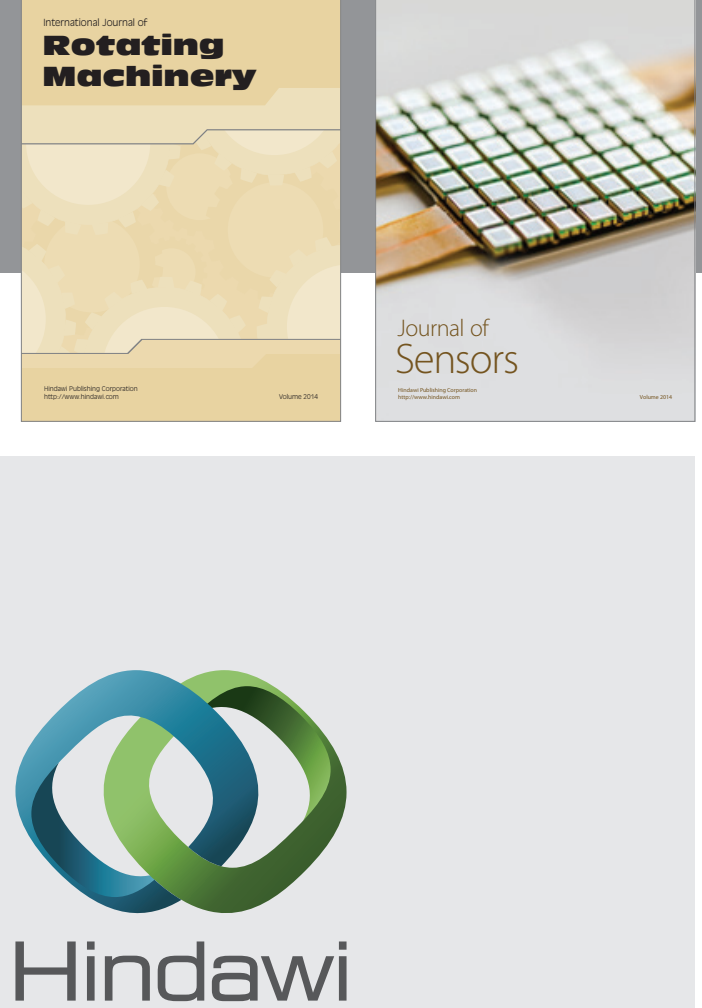

Submit your manuscripts at http://www.hindawi.com
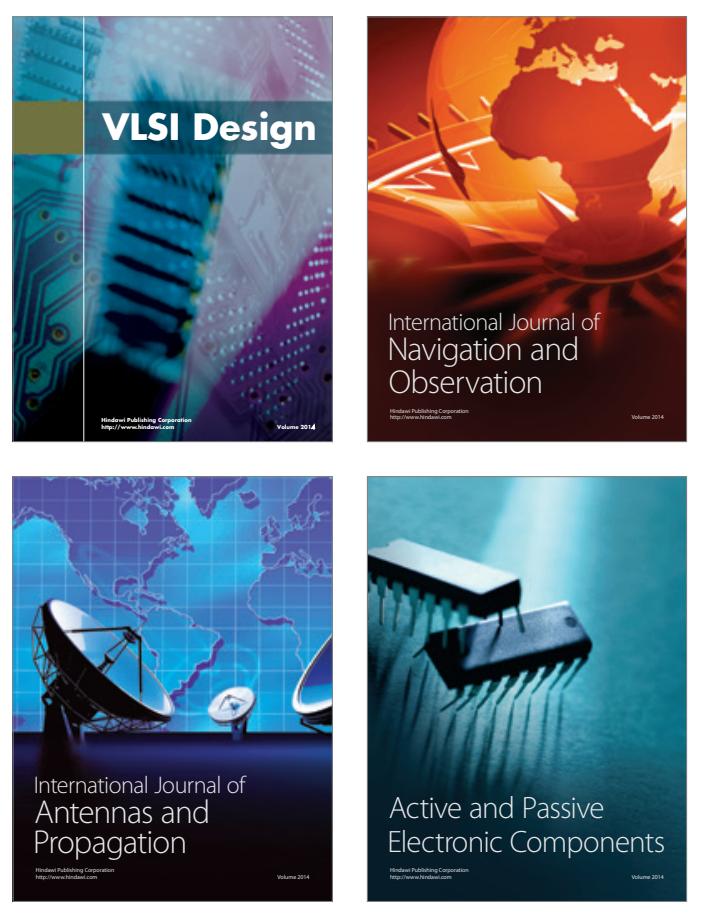
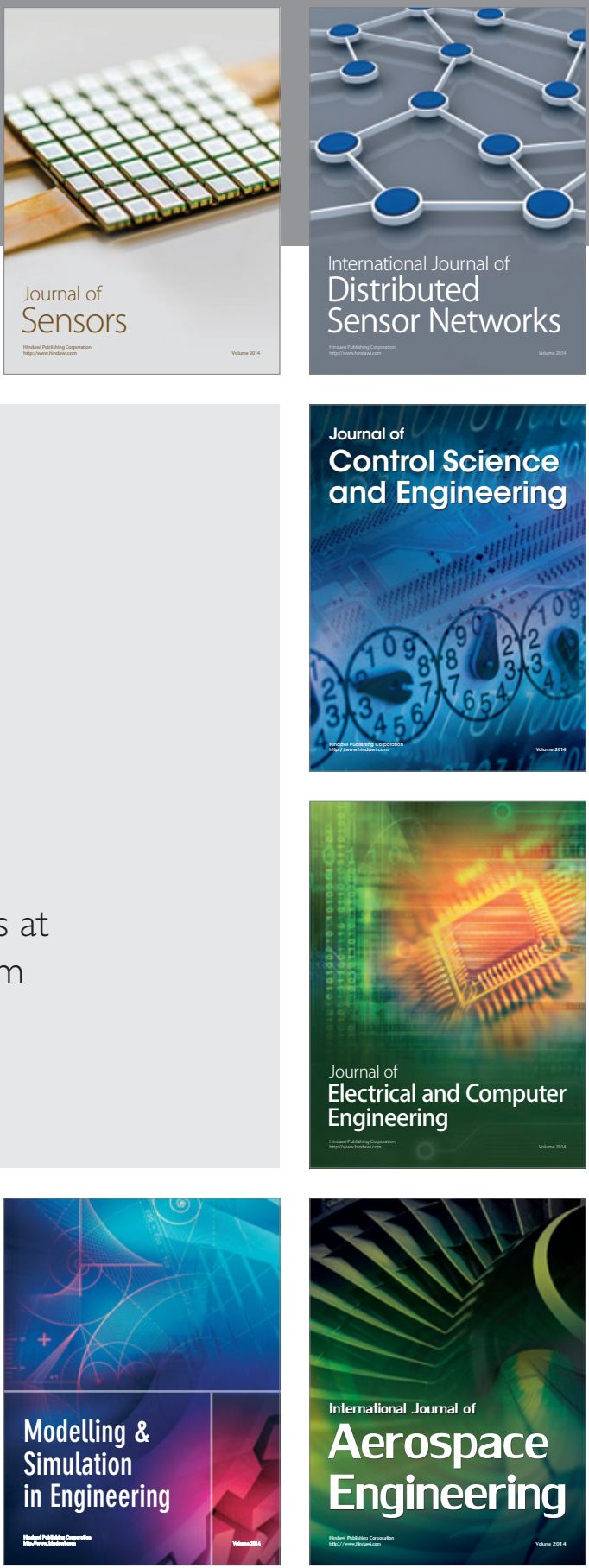

Journal of

Control Science

and Engineering
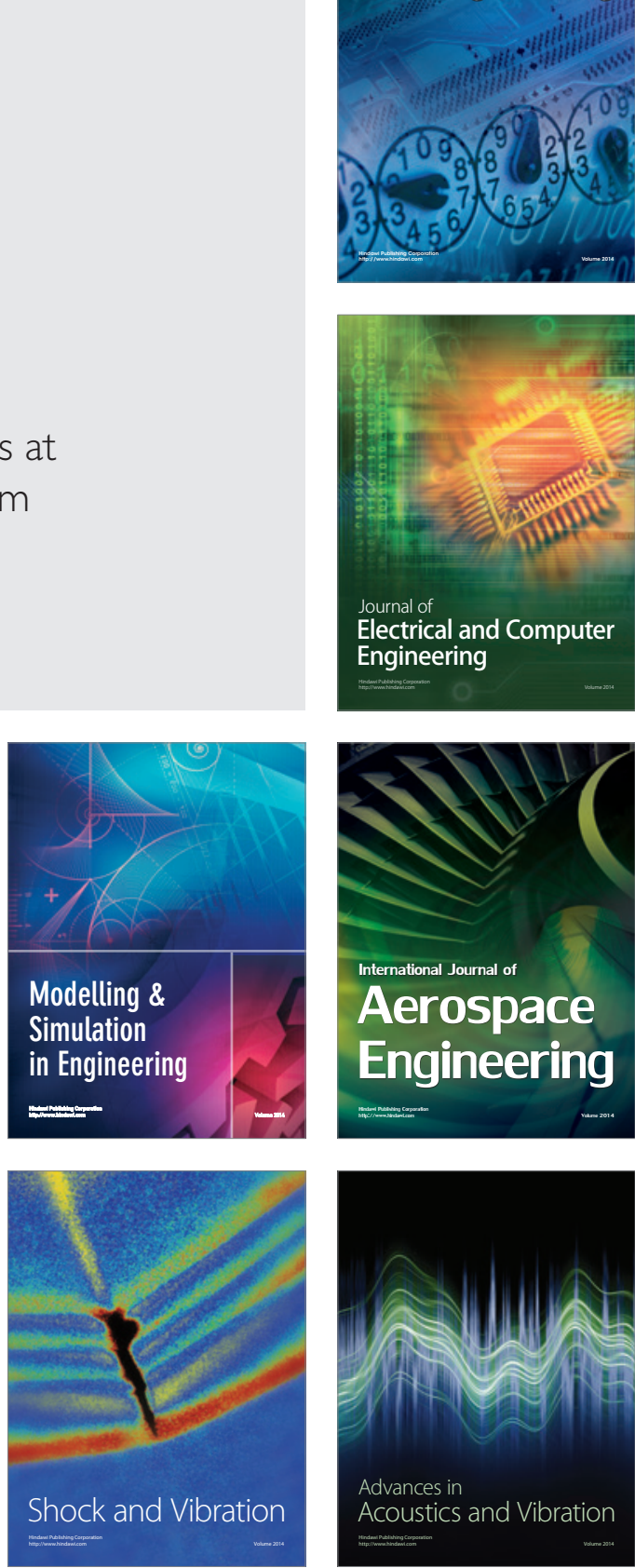